\title{
DEMOCRACIA E ORGANIZAÇÃO NOS PARTIDOS POLÍTICOS: REVISITANDO OS MICROFUNDAMENTOS DE MICHELS
}

\author{
Maria do Socorro Sousa Braga
}

\begin{abstract}
RESUMO
O objetivo deste artigo é resgatar os pressupostos da tese de Robert Michels a respeito da dinâmica organizacional dos partidos políticos marcada por duas tendências supostamente antagônicas: a propensão à concentração de poderes nas mãos de uma oligarquia, de um lado, e, de outro, a aspiração por participação por parte dos demais membros do partido. Um segundo objetivo é verificar como estudiosos do fenômeno partidário vinculados à perspectiva organizacional contemporânea avaliaram a validade dos conceitos de Michels e os prognósticos deste autor sobre a democracia em seus estudos.
\end{abstract}

PALAVRAS-CHAVE: Robert Michels; partidos políticos; organização partidária; oligarquia; participação.

\section{INTRODUÇÃO}

As organizações políticas conseguem ser democráticas internamente? Essa é a questão que orienta este artigo. Para respondê-la, seguiremos o caminho já traçado por aqueles estudiosos que conceberam os partidos políticos como organismos complexos e diferenciados.

Entre as perspectivas teóricas nas quais podemos nos fundamentar para estudar os fenômenos políticos, optamos pelo foco na abordagem organizacional. Dentre as contribuições que se orientaram por esse registro e até hoje alimentam o debate no que tange a relação entre democracia e organização, está o clássico estudo de Roberts Michels, Sociologia dos partidos políticos, escrito no início do século XX. É a partir dos microfundamentos michelianos, foco deste artigo, que iremos examinar como autores filiados à abordagem organizacional avaliaram essa obra e contribuíram para o conhecimento dos partidos como organismos complexos. Para isso, discutiremos, na próxima seção, os argumentos e microfundamentos de Michels sobre a possibilidade da democracia interna nos partidos políticos. Na terceira seção avaliaremos a influência da obra de Michels à teoria da organização partidária por meio do estudo de seus críticos. Finalmente, na última seção, teceremos considerações sobre a atualidade dos microfundamentos michelianos e seus limites para o estudo dos partidos nas democracias da terceira onda democrática, como a brasileira.

\section{REVENDO OS MICROFUNDAMENTOS DE MICHELS SOBRE A POSSIBILIDADE DA DEMOCRACIAINTRAPARTIDÁRIA}

Michels foi um dos primeiros estudiosos a se preocupar com o exame do funcionamento da estrutura interna dos partidos nascidos com a democracia política, bem como os efeitos de vários fatores internos e externos sobre essa estrutura. Antes dele, apenas Ostrogorski (1902) demonstrara interesse em analisar o surgimento do partido moderno na Inglaterra e nos Estados Unidos ${ }^{1}$. Já Michels, como sabemos, desenvolveu seu estudo

\footnotetext{
1 Esses estudos de Ostrogorski tiveram importante influência sobre a elaboração da "lei férrea da oligarquia" de Michels. Entre esses aspectos, cabe salientar a questão suscitada por aquele autor, no que diz respeito a relação do sufrágio universal e a industrialização com a criação de máquinas partidárias que atuavam na mobilização das massas de modo quase militar. Para Ostrogorski, o controle por uma elite oligárquica do aparato organizacional e a manipulação da massa seriam resultados inevitáveis das formações partidárias modernas. Para ele, em decorrência desses processos paulatinamente as diferenças ideológicas tenderiam a desaparecer. Ao fim chega a duas conclusões principais: primeira, que os partidos políticos organizados surgiram para atender às necessidades da democracia de massa e, segunda, que a organização do partido em si é perniciosa.
} 
clássico particularmente a respeito do Partido Social-Democrata Alemão (SPD) ${ }^{2}$, embora sua tese mais geral se referisse aos organismos sociais de ins-piração nitidamente democrática, exemplificados tanto pelo Estado quanto pelos sindicatos e outras formas associativas.

Para Michels, o SPD era o exemplo do partido de massa moderno mais complexo, que, embora concebido como instrumento privilegiado do desenvolvimento da democracia política, tornarase inevitavelmente uma organização oligárquica. Para inferir sua tese, Michels vai investigar todo o processo e as causas que teriam determinado essa transformação nos partidos socialistas de sua época. É importante salientar que, ao discutir o processo por meio do qual a sua "lei férrea da oligarquia" operaria, ou seja, processo pelo qual as elites governantes se transformariam em oligarquias, Michels realizou importante avanço à teoria elitista desenvolvida por Gaetano Mosca e Vilfredo Pareto ${ }^{3}$.

O objetivo de Michels foi demostrar que a democracia era impossível em organizações e sociedades complexas. O tamanho da organização era fundamental para sua tese. A democracia poderia existir em pequenos grupos, mas, mesmo nesses casos, a especialização e a divisão de funções em larga escala, quando necessárias, inviabilizariam a manutenção dos processos democráticos.

Para Michels, fatores mecânicos e institucionais relacionados à natureza das organizações sociais explicariam os fenômenos oligárquicos presentes nos organismos políticos. Para fundamentar sua explicação, ele recorreu a aspectos da sociologia das organizações e da psicologia social. Em relação ao primeiro eixo analítico, Michels argumenta que nenhum partido pode pressentir de uma organização estável e de uma classe dirigente para

\footnotetext{
2 Não é por acaso que Michels vai analisar esse partido, pois ele tinha sido um membro do SPD, até 1907, e esse livro foi até certo ponto, segundo Hands (1971), um produto de sua desilusão com o movimento socialista e com as próprias transformações do SPD já naquele período.

3 Contudo, vale ressaltar que a concepção de Michels foi muito influenciada por esses dois teóricos elitistas. Para Mosca e Pareto toda sociedade se caracterizava pelo predomínio de um grupo minoritário - uma classe política, ou uma elite dirigente - sobre os demais membros da coletividade.
}

alcançar um mínimo de eficácia. No entanto, se por um lado, esses aspectos indicariam uma necessidade estratégica de qualquer tipo de partido político, por outro lado, revelariam também suas limitações enquanto organizações revolucionárias. Isso é o que podemos verificar na passagem a seguir, quando Michels ressalta um aspecto crucial para o surgimento de uma oligarquia no seio de um partido político: o controle exercido pelos dirigentes sobre a estrutura organizacional. "[...] A principal causa da oligarquia nos partidos democráticos é encontrada na indispensabilidade técnica das lideranças. O processo, que começou em consequência da diferenciação das funções do partido, foi concluído com a ajuda de um conjunto de qualidades complexas que os líderes adquiriram pelo fato de terem se separado das massas". Em seguida, ele conclui que "[...] a lei sociológica fundamental que rege inelutavelmente os partidos políticos pode ser assim formulada: a organização é a fonte de onde nasce a dominação dos eleitos sobre os eleitores, dos mandatários sobre os mandantes, dos delegados sobre os que delegam. Quem diz organização, diz oligarquia" (MICHELS, 1982, p. 237-238).

Os dirigentes partidários, portanto, tenderiam inexoravelmente a converterem-se em membros de instituições oligárquicas, seja por serem eles que aos poucos passam a dominar o conhecimento sobre o funcionamento administrativo e operacional da organização e a elaborar as estratégias de relacionamento com os ambientes de atuação do partido político, conformando uma classe profissional afastada dos demais membros partidários; seja por seus interesses distanciamse cada vez mais daqueles fins que motivaram a criação da própria organização, isto é, dos objetivos da maioria de seus filiados. Dessa forma, a elite dirigente acaba direcionando o funcionamento da organização para proveito próprio, tornando-a um fim em si mesma, à parte do mandato recebido $\mathrm{e}$ da vontade dos demais integrantes do organismo político. Para Michels, daí decorreria um segundo problema que seria a questão da perda de legitimidade no processo de oligarquização.

Essa perda de legitimidade é um dos pontos discutidos por Couto (2010, p. 8) em sua análise sobre a conceitualização da oligarquia e do processo de oligarquização. Com esse fim, Couto realizou interessante paralelo entre a análise de Michels e a de Leach (2005) sobre a "lei férrea da oligarquia". "Para esse autor, a oligarquia se define 
como uma concentração de poder ilegítimo nas mãos de uma elite entrincheirada [...] que lança mão de seu poder organizacional para impedir qualquer oposição interna à sua autoridade. Para Michels, nos termos originais da lei férrea da oligarquia, o problema da ilegitimidade do poder é o uso da organização pelos seus líderes de forma a buscar objetivos novos, rejeitados pelos demais; já para Leach, mais importante do que a redefinição dos fins da organização pelos dirigentes é como se estabelece o poder (ou a influência) deles. Considerando isto, os tipos de ilegitimidade do poder seriam três: (1) a ilegitimidade das pessoas, que exercem o poder, mas não teriam recebido um mandato para fazê-lo; (2) a ilegitimidade da jurisdição, que ocorre quando mesmo pessoas dotadas de um mandato legitimamente obtido excedem o âmbito daquilo que lhes é lícito fazer; e (3) a ilegitimidade dos meios, quando o poder é exercido de uma forma não sancionada pelo grupo [...]" (COUTO, 2010, p. 8).

Para chegar a esses argumentos, Michels descreve o processo de oligarquização em duas fases. A primeira diz respeito às origens da liderança e do desenvolvimento da maioria dos partidos, enquanto a segunda busca mostrar como esses dirigentes devem se desenvolver, tornando-se cada vez mais distantes dos demais membros do partido e, portanto, mais oligárquicos.

Para Michels, esse modelo começaria com uma organização baseada na democracia direta, cujo processo de transformação dar-se-ia à medida que o partido começasse a enfrentar problemas com o crescimento do seu tamanho, redundando na necessidade de especialização e na divisão do trabalho intrapartidário, dando origem a formas de delegação e representação. Esses militantes, por sua vez, evoluiriam para a formação de uma minoria dirigente mais permanente, impedindo que houvesse renovação das direções do aparato organizacional. Dessa maneira, aos poucos a centralização administrativa evitaria as iniciativas provenientes dos demais membros da coletividade. Em consequência, argumentaria Michels, a democracia direta nas organizações políticas deixaria de exercer-se, pois não haveria mais a participação de todos na direção desses organismos. Essa mudança acarretaria, segundo o autor, um outro problema crucial para os partidos socialistas: eles, antes revolucionários, ficariam aburguesados ao se acomodarem à lógica do regime democrático liberal, tornando-se inicial- mente uma oposição constitucional para, depois, fazerem parte do próprio aparato estatal.

$\mathrm{O}$ processo de aburguesamento significa que os líderes necessariamente abandonam os "reais" interesses dos demais membros do partido. Da mesma forma, a coletividade pode ser seduzida pelo Estado ou por seus próprios líderes a renunciarem objetivos revolucionários, mas, ao fazêlo, de acordo com Michels, ela trai seus próprios interesses a longo prazo. Independen-temente da forma como analisamos, Michels assume a posição de que o interesse dos líderes partidários e dos burocratas são, por definição, burgueses e, portanto, estão em constante conflito com os da coletividade.

$\mathrm{Na}$ segunda fase do processo de oligarquização, Michels defende que a organização, necessariamente, continuará a se desenvolver, tornandose gradualmente menos democrática e mais oligárquica. Dois tipos de fatores poderiam encorajar os líderes a agirem como oligárquicos. $O$ primeiro diz respeito aos efeitos psicológicos do exercício do poder e ao eixo analítico a que Michels recorre para explicar sua "lei férrea da oligarquia".

De acordo com seu argumento, ao lado das transformações que o próprio exercício de suas responsabilidades impõe à elite dirigente, como a consciência do poder e a crença excessiva na grandeza pessoal, entra em jogo a necessidade que a base de filiados sente por orientação, a rigidez dos grupos e a relativa indiferença da maioria dos membros partidários pela prática efetiva da democracia. Dessa maneira, a coletividade acabaria entregando-se a uma oligarquia, com o objetivo de manter as instituições políticas funcionando.

O segundo fator diz respeito aos efeitos de incentivos seletivos, como o status, os benefícios financeiros e outros a que os líderes partidários teriam acesso por meio de suas ações e políticas. Quanto maiores esses recursos seletivos mais rapidamente acabariam por levar ao aburguesamento dos líderes dos partidos socialistas, o que, por sua vez, afetaria os processos decisórios do aparato partidário, cada vez mais controlados por uma elite oligárquica ${ }^{4}$. Michels também discute

\footnotetext{
4 Ao contrário dessa tendência à oligarquia, Michels observaria que, naqueles contextos com status e remuneração baixos, a liderança tenderia a ser idealista e não oportunista.
} 
as técnicas mobilizadas pelos líderes para manter seu domínio sobre as áreas vitais de um partido, entre as quais estariam a manipulação de suas finanças, o controle sobre a imprensa partidária, a utilização de uma base de poder extrapartidária (como previsto por membros do poder Legislativo) e a "tática de renúncia".

Nessas condições, a democracia nos grandes partidos políticos, segundo Michels, não teria chances de prevalecer, pois a vida partidária seria dominada pelo antagonismo permanente entre duas grandes tendências: a ininterrupta concentração de poderes no aparato organizacional pela elite oligárquica e a aspiração de participação pela coletividade, que cada vez mais se afastaria dos processos decisórios.

Mas como Michels define um partido politico moderno? Para ele seria "uma organização metódica das massas eleitorais". Um partido é visto como sendo essencialmente baseado em seus princípios e doutrinas, pois, para Michels, uma organização partidária não é uma unidade social nem uma unidade econômica. No caso do partido socialista, ele é concebido como um agregado político que procuraria alistar ao mesmo tempo membros e eleitores, apresentando um interesse vital em ganhar sempre mais votos e novas adesões.

Entre os elementos que fariam parte da composição de uma organização partidária, Michels ressalta a importância do programa. Para ele, este programa partidário deve enunciar os princípios norteadores das ações dos seus membros e seguidores. Contudo, argumenta que esse programa poderia até ser a expressão teórica dos interesses de uma determinada classe, mas esse fato não deveria restringir as suas adesões a nenhuma classe social específica.

Ele argumenta que à medida que um partido, mesmo o partido operário, se tornasse uma organização complexa, agregando adeptos de diferentes segmentos sociais, ele não se identificaria necessariamente com a totalidade dos membros filiados, e menos ainda com uma única classe social. O partido moderno acabaria tornando-se, em consequência, um fim em si mesmo, organizando-se ao redor de propósitos e interesses próprios, o que resultaria na separação entre elite dirigente e a classe que representa.

Em termos do distanciamento entre a classe política dirigente e a coletividade de uma organização partidária, outro elemento que contribuiria para isso, segundo Michels, seria o poder centralizador do partido operário, que repousaria sobre os mesmos fundamentos do Estado: autoridade e disciplina. Organizado como um governo em miniatura, essa estrutura seria fatal para sua existência enquanto partido revolucionário.

Outro problema que adviria da organização dirigida segundo princípios burocráticos seria a mudança dos fins originais, os quais passariam a arregimentar o maior número possível de membros. Daí que a luta pelas ideias perderia importância no seio do partido, passando aos poucos a ser concebida como um obstáculo à realização dos seus fins e, por isso, deveria ser evitada por todos os meios possíveis. E essa tendência, para Michels, seria reforçada pelo caráter parlamentar do partido democrático, pois a entrada na disputa eleitoral exigiria cada vez o maior número de votos possível ${ }^{5}$.

Finalmente, quais seriam, segundo Michels, as condições para alcançar a democracia nos partidos? Para ele seria necessário começar a construir um novo modelo, que levasse em conta tanto o aspecto do voluntarismo dos membros, quanto o fato de que a organização partidária é afetada pelas demais instituições políticas do Estado e por suas relações com outros partidos

\section{SOBREA POSSIBILIDADE DADEMOCRA- CIA INTRAPARTIDÁRIA}

O estatuto teórico de Sociologia dos partidos políticos deve-se, em grande medida, aos problemas que esse estudo suscita, contribuindo para estimular, desde sua publicação, em 1911, intenso debate sobre a relação entre democracia e organização, particularmente em organismos como os sindicatos e partidos políticos, e as suposições apontadas por Michels, entre as quais, a tendência inelutável à centralização e à burocratização das organizações de massa ${ }^{6}$.

\footnotetext{
5 Na década de 1980, essas transformações nos partidos socialistas foram retomadas e amplamente discutidas por Adam Przeworski (1989), John Sprague (1986) e Claus Offe (1984).

6 De início, como já era previsível, a obra de Michels teve maior repercussão entre socialistas e teóricos preocupados com os rumos dos movimentos relacionados à classe ope-
} 
É no contexto do pós-guerra, período de florescimento da teoria democrática pluralista, especialmente nos Estados Unidos, e da teoria do desenvolvimento político, em várias regiões do globo, que surgem as críticas mais contundentes à "lei férrea da oligarquia". Essas críticas foram direcionadas a questões tanto metodológicas da pesquisa empírica quanto às unidades conceituais fundamentais à sua tese principal. Devido aos objetivos específicos deste artigo, nós vamos focar este estudo no segundo bloco de inquietações: as imprecisões conceituais.

De acordo com Hands (1971), um dos problemas do trabalho de Michels está na baixa clareza de definições e mesmo distinção entre dois termos cruciais para sua argumentação: organização e burocracia. Para ele, Michels emprega esses dois termos de modo impreciso e vago. Em outras palavras, não parte de um conceito de burocracia rigorosamente definido e hierarquizado. E, embora aceite que a abordagem de Michels esteja intimamente relacionada com a de Max Weber, apresentaria ao menos duas limitações: primeiro, teria levado em consideração apenas alguns aspectos do conceito weberiano; segundo, em contraste com a visão desse estudioso, de burocracia como o ápice do racionalismo, Michels concentraria sua análise em seus aspectos disfuncionais.

Hands destaca que, em algumas ocasiões, Michels refere-se à burocracia como apenas uma forma avançada de organização e, às vezes, aplica o termo a diferentes fenômenos, embora intimamente relacionados. Desse último modo, a organização refere-se à aplicação dos princípios da divisão do trabalho, hierarquia etc., enquanto burocracia estaria mais próxima de um grupo mais ou menos distinto de pessoas que executaria certas funções amplamente especificáveis no interior de uma organização mais ampla.

Outro aspecto criticado por Hands diz respeito à relação que Michels desenvolve entre o crescimento da organização e a sua oligarquização. Para ele, devido ao fato do conceito de organização

rária. Já nos anos 1940, Lipset começou sua pesquisa sobre a democracia sindical, tendo como base o sindicato dos gráficos de Nova York, publicando, em seguida, com Trow e Coleman, 1956, a obra clássica Union Democracy, na qual a "lei férrea" foi refutada, com base na análise da democracia interna. ser multidimensional, Michels somente poderia averiguar essa relação depois de ter precisado o que está entendendo por crescimento. Ademais, teria de especificar quais critérios usaria para medir esse crescimento. Em vez disso, Michels discutiria o crescimento da organização como uma resposta à luta interna do partido (ou sindicato) pelo poder. Em outras partes do seu estudo, ele analisaria o crescimento como se a organização fosse um fenômeno impessoal, quase espontâneo, para o qual não haveria limites muito definidos. Ou, mesmo defenderia a ampliação do aparato organizacional como um processo ilimitado.

Para Hands, a análise de Weber é muito mais consistente sobre esse ponto. Isso porque a análise weberiana enfatiza que o crescimento da administração burocrática ocorre principalmente devido a dois fatores: o crescimento quantitativo de tarefas administrativas e seu desenvolvimento qualitativo. A aplicação dessas ideias aos partidos e a outras organizações, como os sindicatos, revelaria limites bastante definidos à medida que essas instituições são susceptíveis de se organizarem.

Sobre os efeitos desse crescimento organizacional, Hands salienta que, se por um lado Michels parece sugerir que o crescimento da organização eleva o poder dos próprios dirigentes de várias maneiras, por outro lado, ele parece considerar o crescimento de uma burocracia que quer, por si mesma, torna-se dominante sobre os representantes e bases partidárias. Ou que se trata simplesmente de uma ferramenta nas mãos dos líderes para lhes permitir o aumento do seu controle. Michels realmente não separa essas possibilidades e seus argumentos mais específicos não são normalmente direcionados para nenhum dos lados.

A contribuição de Cassinelli (1953) também é fundamental para compreendemos a "lei férrea da oligarquia" de Michels. Em seu estudo, tratou de generalizar essa tese, definindo os seus termos importantes e declarando as suas fontes de evidência. Foi ele um dos primeiros estudiosos a observar que Michels não define com clareza tanto o conceito de organização quanto o de oligarquia. Com esse propósito, discute e analisa esses dois conceitos.

No que tange à definição de organização, depois de propor ampla discussão das características definidoras de uma organização evitando a circularidade das definições fundamentadas nas noções de "líderes" e "fins cooperativos”, Cassinelli defende que não é necessário 
saber o que é uma organização para identificarmos qual é a intenção dela em manter a especialização de funções e as pessoas que realizam essa intenção. Para ele, seguindo Weber, é preciso identificar qual é a especialização própria da organização analisada e qual a persistência ou continuidade no tempo dessa caraterística. Esse aspecto ainda permitiria verificar que algumas organizações são de curta duração. Cassinelli chega ao seguinte conceito de organização, visando a superar essa deficiência do trabalho de Michels: "Uma organização é um grupo de atividades humanas ordenadas por um sistema de funções especializadas; um subgrupo dessas atividades tem como objetivo a manutenção dessa ordem ou de uma ordem muito semelhante a essa" (idem, p. 777).

Já no que diz respeito à elaboração do conceito de oligarquia, Cassinelli discute dois aspectos desenvolvidos por Michels. O primeiro é o de que as pessoas que detêm posições de autoridade dentro de uma organização não são controladas por aqueles que detêm posições subsidiárias. Já o segundo aspecto está relacionado à suposição micheliana de que as pessoas em posições de autoridade perseguiriam seus próprios interesses, ignorando os interesses da coletividade, o que redundaria na exploração da maioria pela minoria dirigente. Cassinelli ressalta duas objeções a essa dimensão. Para ele, primeiramente, seria impossível determinar o que constitui os "interesses" dos líderes e da coletividade antecipadamente, porque uma teoria objetiva do interesse exige que as pessoas definam seus interesses e não que lhes sejam impostos. Em segundo lugar, Cassinelli rejeita tanto a afirmação de que a organização leva necessariamente à exploração quanto a declaração de que conduz à conflitos de interesse, embora neste último caso possa até ocorrer em relação a alguns dos padrões identificados.

Em consequência desses aspectos, Cassinell, identifica no trabalho de Michels um problema de terminologia e uma questão de relação lógica, os quais deveriam ser resolvidos. Explica Cassinelli, que Michels usa o termo "oligarquia" para se referir à "minoria dominante", isto é, a um grupo de dirigentes. Mas, para ele, seria mais razoável usar a palavra "oligarcas" para designar essas pessoas, e reservar "oligarquia" como o nome de uma organização que tem determinadas características, isto é, uma organização que possui oligarcas. Daí que a definição do conceito de oligarquia adotada por Cassinelli é a seguinte: "Uma oligarquia é uma organização caracterizada pelo facto de uma parte das atividades que a compõe, a saber, as atividades que têm o maior grau de autoridade (que tem sido chamadas de atividades de 'liderança' ou 'executiva'), estão livres do controle do restante das atividades organizacionais” (idem, p. 779).

De acordo com Cassinelli, a noção-chave nessa definição é a de liberdade de controle, mas explica que não significa que os líderes possam ignorar completamente as ações e os desejos dos demais membros da organização. Guiando-se por uma abordagem estruturalista, ele defende que essas atividades serão sempre orientadas, pelo menos em certa medida, por considerações a respeito das reações dos liderados. Em outras palavras, liberdade de controle significa que as atividades executivas não são restritas pelas atividades subordinadas no que diz respeito ao seu conteúdo positivo e direção. É neste sentido que as atividades executivas da classe dirigente estariam livres de controle em uma oligarquia. As atividades subordinadas não direcionam a forma (ou mesmo o propósito) das atividades executivas, pois elas teriam apenas uma influência "negativa" ou "restritiva".

Medding (1970), outro importante estudioso da obra de Michels, discute questão chave para este artigo. Ele parte das seguintes questões gerais: dada a impossibilidade da democracia direta, é inevitável o tipo da oligarquia de Michels? Quanto pode haver de participação em organizações complexas, quanta influência e poder podem ser exercidos pela coletividade sobre as decisões?

Para Midding, Michels equivocou-se em suas interpretações sobre a natureza do poder da liderança partidária. Isso porque para ele, Michels não levou em conta as limitações do poder das elites dirigentes, que derivariam da estrutura do partido político como uma organização. Medding argumenta, contudo, que sua discussão se aplica apenas aos partidos políticos que operam dentro de um contexto democrático, no qual a concorrência para obter o poder se dá entre grupos organizados. A principal característica distintiva desses partidos é que eles seriam organizações mais abertas e envolvidas em maximizar o apoio do público interno às políticas e aos líderes. Argumenta ainda que, à medida que esse tipo de partido precisa de amplo apoio de novos filiados, ele tende a ser altamente adaptável, resultando na necessidade de realizar mudanças sociais e 
concessões políticas com o propósito de absorver novos membros. Nessa condições, segundo Midding, o controle oligárquico, conforme defende Michels, seria muito difícil de ser alcançado.

Se, por sua vez, o partido permanecer mais preocupado com a manutenção da homogeneidade social, pureza doutrinária ou seletividade de membros, ele seria menos adaptável àquele ambiente competitivo e, em consequência, o controle oligárquico teria maior probabilidade de se estabelecer. Em outras palavras, para Midding, determinadas características dos partidos, como voluntariedade associativa e a busca do poder nas democracia representativas liberais, as quais resultam na necessidade de amplo recrutamento de filiação partidária e até mesmo em maior apoio do público em geral, combinar-se-iam para reduzir a possibilidade de oligarquização na relação líderseguidor e, ao mesmo tempo, para aumentar o poder e o controle dos seguidores sobre os líderes.

Essa tese alternativa de Midding à "lei férrea da oligarquia", de Michels, foi desenvolvida com base em três pressupostos básicos da teoria micheliana. A primeira categoria analítica discutida é o conceito de poder. De acordo com Midding, na análise de poder de Michels, os interesses de líderes e seguidores das associações complexas (entre as quais os partidos) são necessariamente diametralmente opostos e, ademais, o poder é monopolizado por um pequeno grupo coeso de dirigentes que impõe a sua vontade sobre a coletividade. Assume-se, ainda, que o exercício do poder implica necessariamente uma situação coercitiva ou de conflito em que a vontade de um ator ou demais membros do grupo é ignorada, frustrada ou manipulada pela liderança partidária. Essa visão, para o autor, é inadequada na análise das relações de poder em partidos políticos competitivos baseados em recrutamento político livre e empenhado em maximizar o apoio do público em geral. Por isso ele sugere uma definição mais ampla de poder, adotando a conotação weberiana, segundo a qual é "a chance que um homem ou um grupo de homens tem para realizar a sua vontade mesmo com a resistência de outros que estão participando da ação".

De acordo com a explicação de Midding, a ênfase de Michels em situações de conflito acabou levando-o a se preocupar com a base do poder coercitivo e a negligenciar outros aspectos importantes do poder, como, por exemplo, aquele com base no consenso. Nesse sentido, há dois aspectos importantes do conceito de poder que devem se manifestar dentro dos partidos. O primeiro, inspirado no trabalho de Friedrich (1963), está relacionado a ideia de que se o propósito da ação partidária requer cooperação de vários membros, então o poder dos dirigentes vai repousar na capacidade deles de liderar no sentido de garantir o bem desejado. Já o segundo aspecto, mais próximo da noção parsoniana de poder, se refere aos elementos coletivos de poder, à capacidade de expandir a quantidade de poder em um sistema em oposição ao conceito de soma zero de uma quantidade fixa de poder que é disputada e distribuída em meio à resistência. Isso ocorreria porque o poder consensual é baseado na cooperação, ou seja, quanto maior o grau de cooperação, maior a expansão do poder no sistema. Midding ressalta, portanto, a natureza dual do poder: se por um lado, o poder coercitivo inclui além da ameaça ou do uso de violência física, da ameaça de sanções materiais e psicológicas e privações, e até mesmo o simples medo de sua perda. Por outro lado, o poder consensual, originado na habilidade e necessidade do líder de ganhar a cooperação dos demais integrantes do partido, é o poder sustentado por acordos. Sendo assim, à medida que os líderes demonstram capacidade de conseguir a cooperação de seus seguidores, seu poder crescerá muito. Todavia, quando esses mesmos dirigentes não obtiverem o acordo e cooperação de seus seguidores, o seu poder será limitado. Isso ocorre porque essa forma de poder é baseada na necessidade e no desejo de alcançar um consenso. Para isso, meios normativos de obter obediência irão por si só, muitas vezes, ser suficientes para alcançar esse objetivo. Assim, em uma situação considerada ideal, as decisões políticas do partido serão tomadas após todas as alternativas terem sido consideradas, com grupos concorrentes e indivíduos comprometidos internamente ao menos em parte com o propósito de maximizar acordos que contemplem os diversos interesses envolvidos naquelas questões políticas conflituosas.

Além disso, para Midding, tanto o poder consensual quanto o coercitivo atuariam restringindo influências. Em outras palavras, o poder consensual, quando operando em seu aspecto negativo, que é a massa dos filiados recusando a concordar com uma proposta política, ou a sua rejeição à iniciativa política, exerceria um 
constrangimento poderoso sobre a elite dirigente, podendo ser forçada a abandonar propostas por não contarem com o apoio da coletividade.

A segunda pressuposição de Michels discutida por Midding refere-se à noção de que, pelo fato de os seguidores não poderem iniciar alternativas de políticas específicas e decidir sobre elas, não exerceriam qualquer controle ou influência significativos sobre a tomada de decisão. Para Midding, o mais correto seria afirmar que a tarefa de exercer o controle acabaria sendo mais difícil, embora não fosse impossível. Isso porque ele pressupõe que as escolhas políticas dos membros de um partido (qualquer que seja sua classe social e posição na estrutura partidária) seriam relativamente abertas e variadas. Mas também salienta que para existir o controle sobre os membros partidários, deveria haver oportunidades amplas, claramente definidas e institucionalizadas para possibilitar a oposição aos dirigentes, o que contribuiria para a discussão e participação no processo de tomada de decisão.

Para Midding, no modelo consensual o objetivo dos líderes é atingir e, se necessário criar, um consenso em que todos os membros da coletividade possam participar da mesma forma. Já o modelo oligárquico, ao contrário, ignora $o$ papel da discussão e a busca por compromissos como um método básico de decisão política do partido. Em contraste, o modelo consensual sugere, como regra geral, que a tomada de decisão em partidos competitivos seja o resultado de compromissos assumidos após exaustiva discussão. E, como enfatiza Midding, é particularmente importante nesse processo de formação de consenso em torno de uma política, a participação de o partido como um todo para manter intacta a organização necessária para que consiga promover o seu interesse de longo alcance e de retenção do poder. A necessidade de evitar rachas intrapartidários contribui, assim, para manter a força do partido, redundando no prêmio pelos compromissos acertados por todos os membros do organismo partidário.

Midding adverte, no entanto, que não são todos os partidos políticos passíveis de tomada de decisão consensual. Em geral, quanto mais diverso e agregativo for o partido, maior a probabilidade de que se encaixe no padrão citado, no qual a negociação será o principal mecanismo de tomada de decisão e, a barganha, o mecanismo chave do processo decisório. Em uma organização diversificada, explica, existiriam algumas alternativas para um processo de negociação que ocorreria em vários níveis no interior da estrutura organizacional: entre grupos de líderes e entre os líderes e sublíderes ou ainda entre líderes e seguidores.

As indicações desse processo deveriam ser buscadas, particularmente, no nível estrutural, ou seja, em instituições tais como conferências, mas também no padrão de funcionamento das comissões e subcomissões que satisfaçam os processos de negociação da política e resolva os desacordos políticos. Enquanto a criação de tais comissões é tida como prova prima facie de um processo de negociação consensual, Medding ensina que ainda é preciso ir além e investigar a composição desses comitês (para ver se todos os pontos de vista estão representados) e seu funcionamento atual (e verificar se todos os pontos de vista são apresentados e tidos em conta, e para estabelecer se a solução alcançada representa um compromisso entre os vários grupos partidários ou se não passa da vitória total de apenas um grupo). A vitória total de um grupo, segundo Midding, não seria prova conclusiva de que esse grupo impôs sua vontade sobre os outros, mas sim que tal decisão representou a opinião da maioria e foi atingida depois de uma discussão longa e exaustiva. No entanto, é importante salientar que ainda permaneceria a questão de como esse resultado foi alcançado: se um lado articulou a fim de garantir um acordo ou enfrentou uma clara ameaça do exercício do poder coercitivo. $\mathrm{Na}$ maioria dos casos, Midding ressalta que podemos encontrar algum compromisso entre as partes envolvidas visando chegar a um acordo. Nessa concepção de Midding acerca do poder político numa organização, portanto, todos os que exercem alguma função de liderança estão intimamente ligados com seu próprio conjunto de seguidores, a quem eles devem ser sensíveis e cuja cooperação devem ganhar para manter suas posições. Todos os líderes estariam sujeitos à influência do poder consensual dos seus seguidores e ao processo contínuo de verificação e contra-verificação da formação de compromissos e do consenso que tornam possíveis.

Finalmente, a terceira pressuposição de Michels discutida por Midding diz respeito à estrutura interna dos partidos políticos, ou seja, à distinção de estrutura horizontal entre dominação da liderança e impotência da massa de filiados. 
Consequentemente, para efeito da compreensão da tomada de decisão, o partido seria composto por uma classe dirigente compacta que enfrentaria uma massa homogênea de seguidores. Midding questiona essa ênfase sobre a divisão entre os líderes e liderados porque ignoraria o conteúdo das decisões e dos pontos de vista políticos. Mas como vimos anteriormente, isso não incomoda Michels, cujos pressupostos normativos e cujas teorias de classe simplesmente ignoram outros aspectos de diferenciação social. Assim, todas as outras formas de diferenciação funcional (como, por exemplo, representantes parlamentares, sindicalistas, burocracia do partido) são classificadas segundo uma forma dicotômica da estrutura partidária em que uma liderança burguesa dominante, coesa e controlada por parlamentares enfrenta uma massa proletária homogênea, apática e pouco sofisticada.

De acordo com Midding, o grupo dirigente de Michels é uma variedade da elite de Mosca. No entanto, para ele Michels não teria demonstrado sua existência, pois seu esforço teria sido simplesmente rotular a liderança do partido como uma elite. Defende ainda que os partidos, como todas as associações sociais, também devem ter seus líderes, contudo o mais significativo para ser analisado são os conteúdos das decisões e como exercem o poder. Para isso, deveria ser demonstrado não só que a liderança existe, mas que elas realmente governam ou regulam e administram. Além disso, para esse autor, se os dirigentes dominam de acordo com a teoria de Michels, então também deveria ser demonstrado que os líderes possuem consciência de grupo e coerência, e conspiram para exercer o poder em seu próprio interesse em detrimento e à custa de outros grupos. Michels, segundo Midding, foi capaz de indicar que a entrada em um grupo por um processo de cooptação iria manter intactas as políticas e as perspectivas da elite. No entanto, ao examinar apenas a posição estrutural da liderança, Michels não teria conseguido realizar esse propósito analítico. Este tipo de elite oligarquizada somente poderia ser identificado se ao menos as políticas e o conteúdo das decisões do partido fossem analisados.

Por fim, Midding elabora uma hipótese de pesquisa sobre os limites do poder dos líderes partidários. Para ele, embora os líderes tenham atuações mais decisivas do que os seguidores em atividades partidárias e em aspectos importantes para a coletividade, eles terão de submetê-las às várias formas de veto. Defende que, quanto mais os líderes adequam suas demandas e iniciativas políticas às expectativas e opiniões dos seus seguidores, maior a probabilidade de que eles sejam bem sucedidos. Admitir isso, entretanto, é também aceitar as limitações sobre o poder e a autoridade dos líderes legitimados por seus seguidores. Para Midding, portanto, o problema é empírico. Por isso teríamos que investigar as seguintes perguntas de pesquisa: quanto poder é exercido por quem e de que forma? Quanta influência recíproca e deferência mútua existem? Quem inicia, quem veta, quem compromete, quem recua? Como e por que eles fazem isso?

Muitas dessas elaborações teóricas de Midding, discutidas anteriormente, influenciaram de certa maneira Panebianco (2005), autor do mais recente e sistemático estudo sobre a organização e o poder nos partidos políticos. Para analisar os modelos de partido da Europa Ocidental, Panebianco examina as relações de poder que definem a dinâmica interna do partido, privilegiando as alianças e as lutas dentro da organização como dimensões chave para a compreensão de sua origem, seu funcionamento e transformações. Para esse autor, como também era para Midding, o pressuposto é que a ordem organizativa de um partido é sempre uma ordem negociada, dependente do equilíbrio alcançado entre as várias demandas e pressões exercidas pela coletividade partidária que, por sua vez, também são afetadas pelo ambiente externo.

Um primeiro resultado dessa discussão foi o distanciamento tanto dos estudos críticos quanto dos defensores da tese de Michels sobre o desenvolvimento oligárquico dos partidos. Para isso, Panebianco buscou uma definição precisa de poder organizativo, pois, para ele, essa era uma lacuna importante na maior parte da literatura sobre os partidos até então existentes ${ }^{7}$. Inspirado pela teoria do poder como relação de troca

\footnotetext{
7 De acordo com Panebianco (2005, p. 42), os estudos até então existentes sobre a validade ou falsidade da tese da "lei férrea" de Michels partiam de premissas diferentes, pois apresentavam concepção diversa das características do poder no interior dos partidos. Assim sendo, enquanto para os defensores o poder é definido como algo que se possui e se exerce sobre os outros, para os seus críticos, o poder é uma relação de influência com características, mesmo que diluídas, de reciprocidade. Daí que se explicaria porque as duas vertentes focam em dimensões do poder que sempre coexistem em qualquer partido.
} 
elaborada por Blau (1964), Panebianco definiu o poder como sendo relacional, assimétrico mas recíproco. Em outras palavras, o poder manifestarse-ia numa relação de troca desigual, em que um ator ganha mais do que o outro, contudo, o poder nunca é absoluto, mas é limitado pela própria natureza da interação. Em contrate com a tese de Michels da "lei férrea da oligarquia", portanto, Panebianco defende que a relação de poder entre os dirigentes e a coletividade deve ser concebida como uma relação de troca desigual, na qual os dirigentes ganham mais que os seguidores, contudo devem dar algo em troca. A eficácia dessas trocas, por sua vez, depende do grau de controle que os diferentes agentes têm sobre as chamadas "zonas de incerteza organizativa", ou seja, os recursos organizativos de poder cujo controle permite que determinados atores desequilibrem o poder a seu favor: a competência, a gestão das relações com o ambiente, as comunicações internas, as regras formais, o financiamento da organização e o recrutamento (idem, p. 66). Essa noção implica afirmar que, embora os dirigentes controlem as principais zonas de incerteza, todo ator partidário controla recursos que podem ser empregados nos jogos de poder. Isso ocorreria mesmo com segmentos da base partidária que poderiam, em última instância, apoiar uma elite minoritária ou até mesmo abandonar o partido. Por isso, para Panebianco, é preciso identificar o conteúdo da relação de troca para definir o poder na organização. Nesse sentido, ele ressalta a importância da análise da distribuição dos incentivos pelos dirigentes aos filiados em troca de participação, sejam eles coletivos (de identidade), sejam seletivos (material e destatus).

Como podemos notar, portanto, para Panebianco o controle dos recursos de poder organizativo dificilmente será monopolizado apenas por um grupo interno, como defendia Michels ao discutir a oligarquização organizativa. Ao contrário dessa lógica dicotômica, a premissa de Panebianco é a de que a coalizão dominante será formada justamente pelos agentes que souberem controlar melhor as "zonas de incerteza", o que nos permite supor que haveria maiores chances de diversos grupos comporem a coalizão dominante e, assim, participarem do processo decisório do partido.

Um último ponto a ser discutido nesta parte do artigo, com o propósito de identificar aspectos no trabalho de Panebianco que o distancia do de Michels, diz respeito à tese micheliana segundo a qual a institucionalização do partido provocaria a substituição dos seus fins oficiais pela sobrevivência da organização. Para Panebianco, no entanto, nas organizações institucionalizadas haveria um processo de articulação dos fins por meio dos quais os objetivos oficiais seriam adaptados às exigências e transformações organizativas. Essa noção tem implicações fundamentais para a compreensão das transformações ocorridas nos partidos socialistas, como o SPD alemão, examinado por Michels. Segundo Panebianco (2005, p. 32), na história desses partidos a diferença entre a práxis reformista e a linguagem revolucionária seria compreendida corretamente se tivesse sido interpretada como um processo de articulação dos fins, uma vez que, para ele: “[...] a meta originária (a revolução, o socialismo) é constantemente reafirmada porque dela depende a identidade coletiva do movimento; por outro lado, as estratégias eleitas, pragmáticas e reformistas, garantem a estabilidade organizativa sem, contudo, tirar muita credibilidade da tese de que se está sempre 'trabalhando' para a obtenção dos objetivos oficiais. De fato, a práxis reformista quotidiana é sempre justificada com a tese segundo a qual as reformas não estão em contraste com, mas representam uma passagem intermediária no caminho do socialismo" (idem, p. 32-33).

Em resumo, desde que Michels elaborou a sua famosa "lei férrea da oligarquia" surgiu imensa literatura destinada a indicar provas a favor ou contra quaisquerde suas teses. Embora neste artigo tenham sido discutidos apenas alguns desses últimos estudiosos, é possível verificar que aqueles que concordam com a "lei férrea" argumentam, utilizando-se da longa permanência de determinados atores no controle de muitos partidos, da sua capacidade de manipular os congressos gerais e outras instâncias partidárias por meio de técnicas plebiscitárias, entre outras formas. Já os que negam sua validade geralmente defendem o argumento de que numa associação voluntária para os dirigentes governarem com razoável estabilidade teriam que necessariamente levar em consideração a vontade da coletividade. Ademais, esses estudiosos defendem que se verificaria, na maior parte dos casos, um acordo substancial entre os vários membros do partido sobre as questões políticas conflituosas.

Nos estudos mais recentes, a "democracia" ou a sua ausência são buscadas, normalmente, na maneira pela qual são tomadas as decisões sobre 
a seleção dos candidatos aos cargos públicos eletivos.

\section{CONSIDERAÇÕES FINAIS}

$\mathrm{Na}$ tentativa de compreender a natureza complexa das relações de poder dentro dos partidos políticos de sua época, Michels, em Sociologia dos partidos políticos, formulou uma das teses clássicas que vem desde então motivando importante debate sobre os problemas enfrentados pelas organizações representativas no que tange, especialmente, a como o poder é distribuído no seu interior, como se reproduz, como se modificam essas relações de poder e com quais conseqüências organizativas.

A partir desse estudo seminal de Michels, este artigo teve como principal objetivo resgatar os pressupostos da tese micheliana a respeito da suposta inevitável dinâmica organizacional dos partidos políticos marcada por duas tendências antagônicas: a propensão à concentração de poderes nas mãos de uma oligarquia e a aspiração de participação pela coletividade. Um segundo objetivo foi verificar como estudiosos do fenômeno partidário vinculados à perspectiva organizacional contemporânea avaliaram os conceitos de Michels em seus estudos.

Como vimos, a teoria política elitista de Michels enfatiza que o poder de uma elite repousaria sobre suas habilidades organizacionais. Por isso, para ele, cada organização produziria sua elite. Esse fato, mais que uma regularidade observada empiricamente, seria, em termos epistemológicos, uma "lei da natureza". Em outras palavras, em qualquer grande organização a liderança inexoravelmente se tornaria uma necessidade. A natureza de qualquer organização seria tal que as atividades de liderança ficariam livres de controle e nunca poderiam ser totalmente responsabilizadas por aqueles membros que ocupariam posições subsidiárias dentro da organização. Assim, enquanto a organização seria inevitável em contextos como as sociedades complexas e democracias de massas, qualquer aparato organizacional que atingisse determinado tamanho e certo grau de complexidade também, inevitavelmente, produziria uma situação de dominação de líderes sobre seus seguidores, com a oligarquizarão como consequência. Também foi visto que, dos dois conjuntos mais amplos de mecanismos causais que produziriam o processo de oligarquização, isto é, o técnico e o psicológico, o primeiro (divisão do trabalho, especialização e a indispensabilidade técnica da liderança) seria consideravelmente mais importante.

Por meio do estudo do SPD, Michels buscou demonstrar que as organizações do partido, até que fossem formalmente organizadas de acordo com um modelo de democracia interna, não poderiam evitar ser dominadas e controladas por uma elite irresponsável. O corolário é que a lei férrea deveria se aplicar a todos os partidos políticos que tivessem pouca ou nenhuma preocupação com a democracia intrapartidária. Além disso, essa lei teria uma abrangência que envolveria não somente os partidos numa democracia de massa, mas também todas as organizações grandes e complexas.

O que é mais importante reconhecer neste artigo é a relevância de sua teoria para uma das questões cruciais no mundo contemporâneo no que tange à relação entre partido e democracia de massas. Afinal até que ponto os partidos políticos devem ser vistos como obstáculos ou a própria antítese da democracia? A conceituação de Michels de "democracia" é bastante ambígua, como também é a sua resposta para essa pergunta. No entanto, se a democracia interna do partido é uma precondição para a democracia ou se a lei férrea da oligarquia deve se aplicar também à organização do próprio Estado, Michels sugere que deveríamos ser pessimistas quanto às chances plenas da realização da democracia. No entanto, como o próprio Michels argumenta, depois Duverger (1954) e mesmo Weber (1967 [1918]) em a Política como vocação, as formas iniciais dos partidos se reduziam a pequenos grupos de notáveis e que, somente com a introdução da democracia de massas foi produzido um novo tipo de partido com uma organização forte e permanente. Isto teria sido facilitado pela psicologia dos filiados e a autoridade carismática do líder do partido, redundando em "máquinas" que tinham tomado uma forma plebiscitária e estavam sendo dominadas por uma elite política ou um único líder.

É importante enfatizar ainda, seguindo Weber, que as formas modernas de organização partidária, originadas com a democratização dos direitos políticos, incentivaram o desenvolvimento de um aparato organizacional de associações aparentemente democrático, o que contrasta com os velhos tipos de partido criados na Europa Ocidental. Embora Weber apresente poucas dúvidas sobre 
as implicações dessa evolução para o sistema político, também deve ser notado que a sua interpretação da relação entre a liderança política e a democracia é muito otimista. Sendo assim, enquanto para Ostrogorski e Michels a ausência de democracia interna nos partidos minaria todo o sistema democrático, na análise weberiana, uma liderança forte e responsável politicamente seria uma necessidade para o bom funcionamento da democracia. Isto seria assim porque, a menos que o partido fosse controlado por uma forte liderança política, a burocracia poderia, em virtude da eficiência de sua organização, facilmente obter uma posição política predominante e se tornar o grupo governante de fato, sem prestar contas ao público. Nesse sentido, os dirigentes políticos responsáveis por princípios seriam, portanto, necessários para garantir os funcionários burocráticos na "administração imparcial" dos partidos, sem, contudo, envolver-se em política.

Em suma, de acordo com as reflexões de Michels acerca dos partidos políticos iniciais, emergentes na virada do século XX, a ausência de democracia interna nesses organismos teria sérias implicações sobre a própria existência do regime democrático. Como ele mesmo afirma: " $\mathrm{A}$ democracia é, ela também, um tesouro que ninguém nunca poderá trazer à luz. Mas continuando as investigações e pesquisando incessantemente para encontrar o desconhecido, não deixaremos de realizar um trabalho útil e fecundo pela democracia" (MICHELS, 1982, p. 241).

Contudo, a maioria de seus contemporâneos reconhece que as instituições políticas em um contexto de democracia de massas, quando passasse a predominar a noção de partido como intermediário necessário entre os cidadãos e o Estado, tornar-se-iam fundamentais para o funcionamento e a governabilidade na democracia liberal. Com as transformações e crise em curso nos partidos europeus de meados do século XX em diante, decorrentes, por um lado, de mudanças ambientais relacionadas ao sistema de estratificação social e, por outro lado, de mudança de tipo tecnológico, vinculada à reestruturação da comunicação política a partir dos efeitos dos meios de comunicação de massa e, principalmente, da televisão, vêm contribuindo para os partidos se organizarem com base no modelo profissionaleleitoral, conforme tipologia formulada por Panebianco (2005, p. 518).

Maria do Socorro Sousa Braga (msbraga2009@gmail.com) é Doutora em Ciência Política pela Universidade de São Paulo (USP) e Professora da Universidade Federal de São Carlos (Ufscar).

\section{REFERÊNCIAS BIBLIOGRÁFICAS}

CASSINELLI, C. W. 1953. The Law of Oligarchy. American Political Science Review, Washington (DC), v. 47, n. 3, p. 773-784, Sept.

COOK, P. J. 1971. Robert Michels' Political Parties in Perspective. The Journal of Politics, Cambridge (UK), v. 33, n. 3, p. p. 773-796, Aug.

COUTO, C. G. 2010. Oligarquia e processos de oligarquização: um problema institucional das organizações. Artigo apresentado no VII Encontro da Associação Brasileira de Ciência Política, realizado em Recife (Pernambuco), de 4 a 7 de agosto. Digit. Disponível em: http:/ /cepesp.fgv.br/sites/cepesp.fgv.br/files/ Couto\%20(Oligarquia).pdf. Acesso em: 15.out.2012.

DUVERGER, M. 1987. Os partidos políticos. Rio de Janeiro: Guanabara.
FRIEDRICH，C. J. 1963. Man and His Government: An Empirical Theory of Politics. New York: McGraw Hill.

HANDS, G. 1971. Roberto Michels and the Study of Political Parties. British Journal of Political Science, Cambridge (UK), v. 1, n. 2, p. 155172, Apr.

LEACH, D. 2005. The Iron Law of What Again? Conceptualizing Oligarchy Across Organizational Forms. Sociological Theory, Malden, v. 23, n. 3, p. 312-337, Sept.

MICHELS, R. 1949. Political Parties: A Sociological Study of the Oligarchical Tendencies of Modern Democracy. New York: Free.

1982. Sociologia dos partidos politicos. Brasília: UNB. 
MEDDING, P. Y. 1970. A Framework for the Analysis of Power in Political Parties. Political Studies, Malden, v. 18, n. 1, p. 1-17, Mar.

OFFE, C. 1984. Problemas estruturais do Estado capitalista. Rio de Janeiro: Tempo Brasileiro.

OSTROGORSKI, M. J. 1970. Democracy and the Organization of Political Parties. New York: Haskell.

PANEBIANCO, A. 2005. Political Parties: Organization \& Power. Cambridge (UK): Cambridge University.
PIZZORNO, A. 1966. Introduzione allo studio della participazione política. Quaderni di Sociologia, v. 15 , n. $3-4$, p. $235-287$, lug.-dic.

SARTI, I. 1996. A utopia de Michels e a democracia partidária em perspectiva. Revista Brasileira de Ciências Sociais, São Paulo, v. 30, n. 11, p. 129-137. Disponível em: http:// www.anpocs.org.br/portal/publicacoes/ rbcs_00_30/rbcs30_12.htm. Acesso em: 15.out.2012.

WEBER, M. 1967 (1918). Ciência e política: duas vocações. São Paulo: Cultrix. 
DEMOCRACY AND ORGANIZATION WITHIN POLITICAL PARTIES: REVISITING THE MICRO-BASIS OF MICHELS' WORK

\section{Maria do Socorro Sousa Braga}

My goal here is to return to the premises of Robert Michels' thesis on the organizational dynamics of political parties, marked by two supposedly antagonistic tendencies: the propensity toward the concentration of powers in the hands of an oligarchy, on the one hand, and desires for participation on the part of other party members, on the other. I also look at how scholars of the political party 
REVISTA DE SOCIOLOGIA E POLÍTICA V. 20, Nº 44: 199-203 NOV. 2012

phenomenon tied to contemporary organizational perspectives evaluate Michels' concepts and the prognosis for democracy that emerges from his studies.

KEYWORDS: Robert Michels; Political Parties; Political Party Organization; Oligarchy; Participation. 
LA DÉMOCRATIE ET L'ORGANISATION DANS LES PARTIS POLITIQUES : UNE ANALYSE DES MICRO-FONDEMENTS DE MICHELS

\section{Maria do Socorro Sousa Braga}

L'Objectif de cet article c'est de reprendre les présupposés de la thèse de Robert Michels par rapport à la dynamique organisationnelle des partis politiques marquée par deux tendances supposées antagoniques : 1'inclination à la concentration de pouvoirs dans les mains d'une oligarchie, d'un côté, et, de l'autre, l'aspiration des autres membres du parti pour de la participation. Un autre objectif, c'est celui de vérifier comment les spécialistes du phénomène partidaire liés à la perspective organisationnelle contemporaine ont évalué la validité des concepts de Michels et le prognostiques de cet auteur sur la démocratie dans ses études.

MOTS-CLÉS: Robert Michels; partis politiques; organisation partidaire; oligarchie; participation. 